\title{
Experimental investigation of UV tolerance in hermatypic corals (Scleractinia)*
}

\author{
Otto Siebeck
}

Zoologisches Institut, Universität München, Luisenstraße 14, D-8000 München 2, Federal Republic of Germany

\begin{abstract}
Effects of artificial radiation on various species of coral from the Great Barrier Reef were studied. The corals were either exposed to artificial white light during and after UV-treatment or were kept in darkness subsequent to UV exposure. When not exposed to white light, the UV tolerance of corals taken from depths of up to $1.5 \mathrm{~m}$ was, on average, double that of those collected at 18 to $20 \mathrm{~m}$. Under the influence of short wavelength visible light (max. effectiveness 450 to $500 \mathrm{~nm}$ ), UV tolerance increased on average by a factor of 6 . It is postulated that protection from UV light involves at least 2 different physiological mechanisms: screening by UV-absorbing compounds and recovery due to photoreactivation. The most conspicuous symptom of serious radiation damage to polyps was extrusion of mesenterial filaments through the mouth opening and entire body surface. Similar but less pronounced reactions could be induced in non-irradiated polyps by exposing them to radiation-damaged polyps, in particular when the unexposed polyps were a different species. Such interactions never occurred, however, between polyps from the same colony. It is therefore conjectured that there is a specific protective mechanism that impedes the spread of secondary damage from damaged polyps to others in the same colony.
\end{abstract}

\section{INTRODUCTION}

Measurements by Jerlov (1950) showed that oceanic waters transmit considerable amounts of UV radiation, yet the previously held view that UV-light is without ecological importance in all types of waters remained predominant for a considerable period. Within the last $10 \mathrm{yr}$, however, numerous observations have given impressive support to Jerlov's view of the importance of UV (see Calkins 1982 for review). Research nowadays is concerned with more specific questions such as the effects caused by UV radiation and the depths at which such effects can be detected (Karanas 1979, Damkaer et al. 1980, Jokiel 1980, Worrest 1982). The thickness of the ozone layer in the upper stratosphere has been observed to be decreasing progressively (Farman et al. 1986) leading to fears that this, in turn, will cause more UV-light to reach the earth's surface. Questions have arisen concerning the possible resulting damage to plants and animals (Calkins 1982). Such questions focus on UV tolerance, possible differences in tolerance depending on the extent of radiation exposure, and adaptation to changed levels of radiation.

It is known that UV-induced damage attributable to

- Dedicated with esteem to Professor Dr H.-J. Elster, Konstanz, FRG, on his 80th birthday primary damage of nucleic acids can be repaired, to a certain extent, by endogenous mechanisms (see review by Kiefer \& Wienhard 1977). Hence, in addition to specific behavioural responses (causing organisms to avoid dangerous areas), physiological mechanisms must also be taken into consideration. Such mechanisms include, in particular, the screening of sensitive cell structures by suitable compounds and the repair of primary UV-induced damage. Adaptation to increased UV irradiation would therefore be possible, at least in principle, both by augmenting the screening effect (by increasing the concentration of the relevant compounds) and by increasing the capacity for repair.

Investigations carried out on planktonic crustaceans from habitats exposed to different UV levels (e.g. from shallow mountain waters and deeper flatland lakes) have shown considerable differences in the UV tolerance of these organisms (Siebeck \& Böhm 1986). Since these motile organisms are also capable of utilizing effective behavioural responses so as to avoid UV radiation (e.g. by migrating to lower depths), physiological mechanisms are only partially involved in ensuring survival. Sessile organisms, on the other hand, are dependent almost exclusively on physiological mechanisms for UV tolerance but, to a certain extent, also on adaptation to higher radiation levels. It thus appeared advisable to augment the results obtained 
from planktonic crustaceans with investigations on sessile organisms. Corals from the clear waters (high UV transmission) of the Great Barrier Reef on the east coast of Australia offered a promising system to examine.

\section{MATERIALS AND METHODS}

Experiments were carried out during three $6 \mathrm{wk}$ stays $(1981,1984,1987)$ at the Australian Institute of Marine Science, Townsville, Queensland. The following species were used: Goniastrea edwardsi (Chevalier 1971), Goniastrea pectinata (Ehrenberg 1834), Favia matthei (Vaughan 1918), Favia favus (Forskal 1775), Favia pallida (Dana 1846), Favites complanata (Ehrenberg 1834), Platygyra sinensis (Milne Edwards et Haime 1848), Montastrea curta (Dana 1846) and Coeloseris mayeri (Vaughan 1918).

Corals were usually delivered as fragments from larger colonies. When their surface area was substantially larger than $300 \mathrm{~cm}^{-2}$, they were broken into correspondingly smaller pieces and kept in aquaria at ca $22^{\circ} \mathrm{C}$ with continuous water exchange.

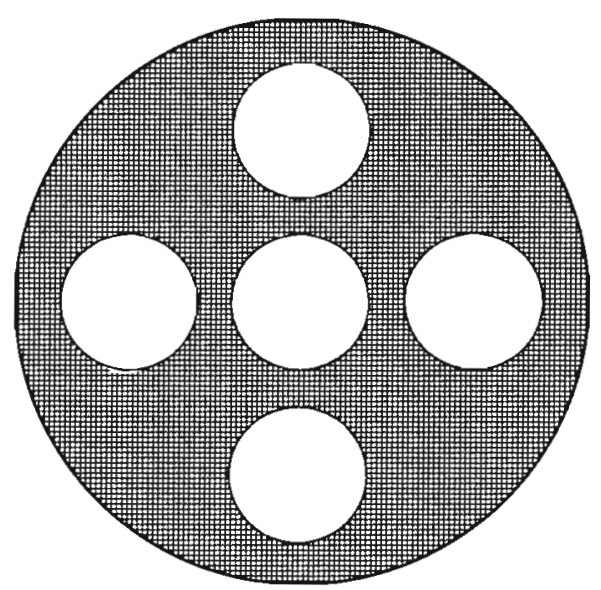

A

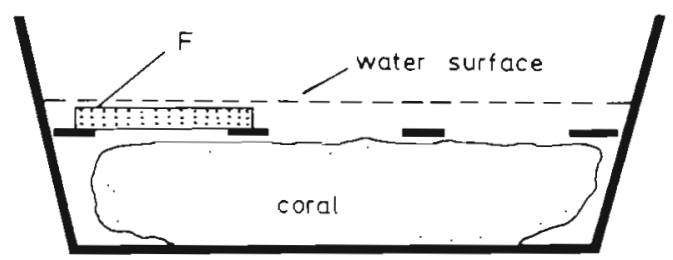

B

Fig. 1. (A) Plexiglas disc with openings (top view). (B) Irradiation vessel containing the coral colony with Plexiglas plate above. Optical filters (F) can be placed over the openings (cross section). (Modified from Siebeck 1981)
Experiments were started after 2 to 3 d of observation when it was certain that removal from the reef, transport and fragmentation had not caused damage (e.g. discoloration, fungal infection) to the central portion of the colony. To keep coral consumption to a minimum, only a small section, not the total fragment, was irradiated during a single experiment. The coral was covered with a black Plexiglas disc containing 5 circular openings ( $5 \mathrm{~cm}$ ) (Fig. 1). Thus, except for the 5 areas, each of which measured $19.6 \mathrm{~cm}^{2}$, the entire coral was covered. This method made it possible to carry out 5 experiments on a single coral sample.

Each of the 5 irradiated areas was treated as a single individual since no significant differences with respect to treatment could be found between the polyps in a single area. They could thus serve as 5 parallel trials with the same dose $\left(\mathrm{J} \mathrm{m}^{-2}\right)$ or as 5 trials with different doses. Preliminary experiments showed that no appreciable interaction took place between polyps from different irradiated areas. During all UV irradiation, the polyps within the irradiated fields were covered with $10 \mathrm{~mm}$ of water and positioned horizontally at a distance of $30 \mathrm{~cm}$ from the UV lamps. The Plexiglas discs were removed after irradiation, and the corals were maintained and observed for another 2 to $4 \mathrm{~d}$ in $5 \mathrm{l}$ containers. The water was aerated vigorously and kept at $22^{\circ} \mathrm{C}$. The source of UV irradiation consisted of 2 parallel Philips TL $40 \mathrm{~W} / 12$ fluorescent tubes (Fig. 2).

The experiments discussed in this paper fall into 4 different groups. The first group consisted of experiments in which the corals were kept in darkness after UV-irradiation thus excluding subsequent photoreactivation. Different UV doses were tested for their effect on the coral. In each case, the respective $\mathrm{LD}_{50}$ value was determined, i.e. that dose at which $50 \%$ of the irradiated samples died

The second group included experiments in which the corals were exposed to artificial daylight for $48 \mathrm{~h}$ after UV-irradiation. Artificial light was provided using 2 parallel Osram L 25 W/19 'daylight' fluorescent tubes (Fig. 2). As in the experiments in the first group, the effects of different UV doses were investigated and the respective $\mathrm{LD}_{50}$ values determined.

In the third group of experiments, coral samples were exposed to the same artificial daylight but different spectral filters were used for $48 \mathrm{~h}$ subsequent to UVirradiation. The UV dose was selected such that all samples would have been killed had they not been subsequently exposed to visible light, but had been kept in darkness. The validity of this assumption was verified in control experiments. Subsequent exposure to visible light (in a predetermined spectral band) enabled coral samples to survive. This percentage of survivors was equated as 1 at maximum effectivity. 


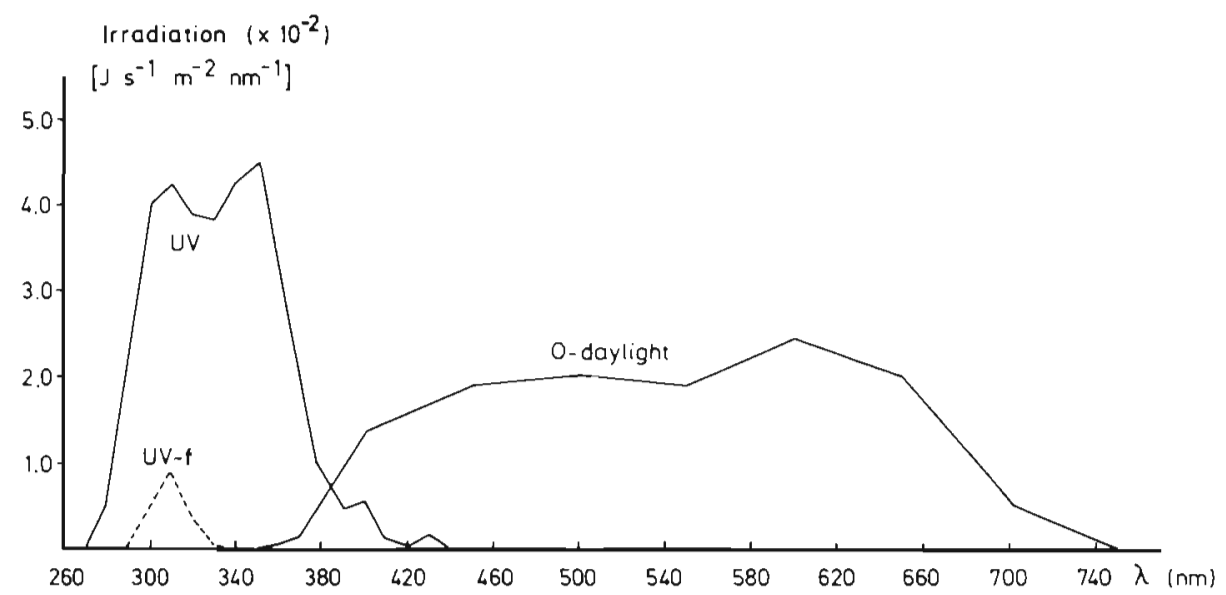

Fig. 2. Spectral energy distribution of the UV lamps without SFK filter (UV) and with SFK filter (UV-f) and of the Osram 'daylight lamps' (0-daylight)

The fourth group of experiments involved studies of non-irradiated corals which were placed in the same water as other coral samples exposed to substantial, but not necessarily lethal, doses of UV-irradiation. These experiments were conducted as follows: Two vessels ( $A$ and $B$ ) were interconnected by 2 tubes and $a$ peristaltic pump to ensure a continuous exchange of water. At an exchange rate of $50 \mathrm{ml} \mathrm{min}{ }^{-1}$ the water in a vessel with a capacity of 1.51 will be changed once every $30 \mathrm{~min}$. The coral in Vessel A was irradiated at a dose which inflicts considerable sublethal radiation damage. The other coral in Vessel B was not irradiated. The concentration of DOC (dissolved organic carbon) was determined at various time intervals according to the method of Müller \& Bandaranayaka (1983).

\section{RESULTS}

\section{Depth-dependent differences in UV-tolerance}

In 1981, corals were collected either from depths of 1 to $3 \mathrm{~m}$ or from depths of 5 to $10 \mathrm{~m}$. It was found that the differences in UV tolerance were considerable (Siebeck 1981). Even greater differences were demonstrated in 1984, when corals were collected at greater depths and in narrower regions: (1) between 0 and $1.5 \mathrm{~m}$ and (2) between 18 and $20 \mathrm{~m}$. Results presented in this section are derived from experiments in which the corals were kept in darkness after UV-irradiation, thus excluding possible photoreactivation due to subsequent exposure to visible light.

The difference in the $\mathrm{LD}_{50}$ dependent on the depth is given as a ratio in which the $\mathrm{LD}_{50}$ determined with corals from shallow water is set at 1 . Hence the dose modification factor (DMF) is $\mathrm{LD}_{50} \mathrm{sh} / \mathrm{LD}_{50} \mathrm{dp}$ where $\mathrm{sh}=$ corals from shallow water and $\mathrm{dp}=$ corals from deep water.
The $\mathrm{LD}_{50}$ values summarized in Table 1 show that corals collected at depths of 18 to $20 \mathrm{~m}$ were approximately twice as UV-sensitive as those from shallow waters. The results of all experiments so far are found in Fig. 3B. The depth is given as the mean depth at which the corals were collected. It is clearly seen that the $\mathrm{LD}_{50}$ values decrease with increasing depth; that is, as UV-sensitivity increases.

Fig. 3 further demonstrates that there can be considerable differences in tolerance between different species even when these have been taken from the same depth. For example, Favita pallida from 1 to $3 \mathrm{~m}$ depth has an $\mathrm{LD}_{50}$ of $178 \mathrm{~kJ} \mathrm{~m}^{-2}$, and from depths less than $1 \mathrm{~m}$, of $240 \mathrm{~kJ} \mathrm{~m}^{-2}$, whereas Favites complanata from less than $1 \mathrm{~m}$ has a $L D_{50}$ of only $96 \mathrm{~kJ} \mathrm{~m}^{-2}$. Further examples have been summarized in Siebeck \& Böhm (1986).

\section{Importance of short wavelength visible light in UV-tolerance}

If the corals are not kept in darkness after UV exposure, as described in the previous section, but irradiated with short wavelength visible light, the $L D_{50}$ values are considerably higher. It thus appears that,

Table 1. Relative $\mathrm{LD}_{50}$ values of corals from shallow (sh) and deep water $(\mathrm{dp})$. Differences between original data $\left(\mathrm{LD}_{50} \mathrm{sh}-\right.$ $\mathrm{LD}_{50} \mathrm{dp}$ ) are significant at $95 \%$ confidence level

\begin{tabular}{|lcc|}
\hline Species & $\begin{array}{c}\text { Shallow water } \\
\text { (up to } 1.5 \mathrm{~m})\end{array}$ & $\begin{array}{c}\text { Deep water } \\
(18-20 \mathrm{~m})\end{array}$ \\
\hline Favia favus & 1.9 & 1 \\
Favia pallida & 2.1 & 1 \\
Goniastrea edwardsi & 2.1 & 1 \\
Platygyra sinensis & 2.5 & 1 \\
\hline
\end{tabular}




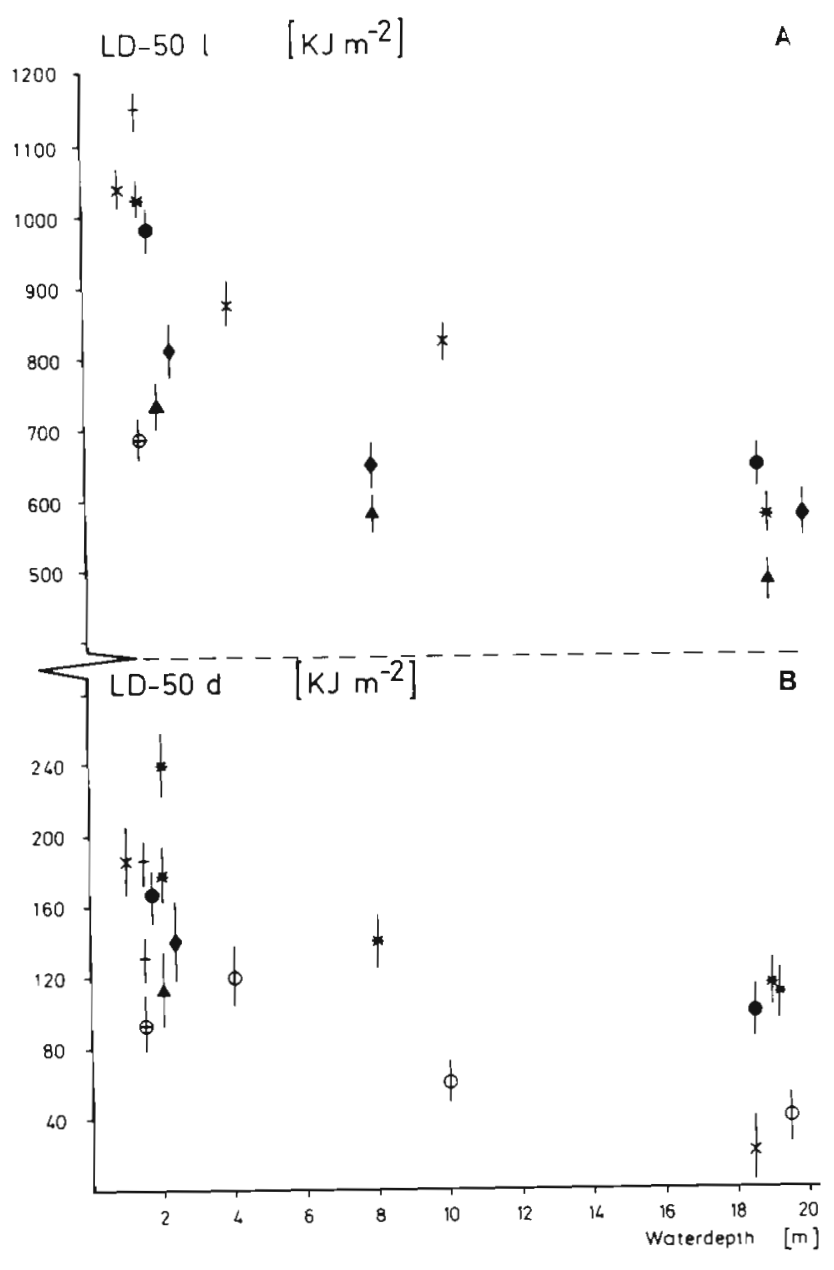

Fig. 3. (A) $L D_{50} l$; (B) $L D_{50}$ d in relation to depth from which the corals were collected. (*) Favia pallida; ( $\times$ ) Favia favus; ( $\mathbf{\text { ) }}$ Favia matthei $i_{i}(\oplus)$ Favites complanata; $(0)$ Coeloseris mayeri; $(\bullet)$ Goniastrea edwardsi; (-) Goniastrea pectinata; $(\bullet)$ Piatygyra sinensis. Bars are $95 \%$ confidence intervals. 1: with visible light irradiation after UV exposure; d: darkness after

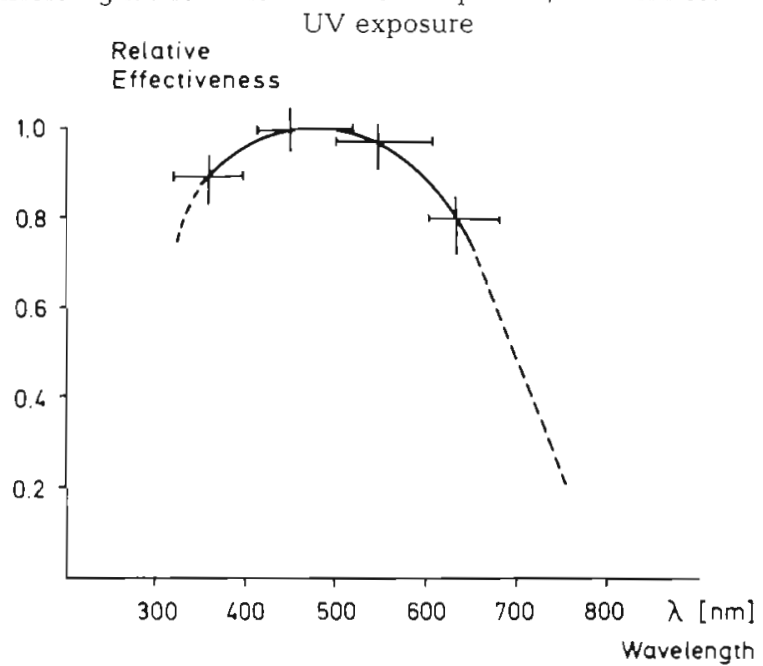

Fig. 4 Favia favus. Relative effectiveness of various spectral regions. Maximum effectiveness $=1$ Vertical lines indicate wavelengths of maximum irradiation, horizontal lines indicate the irradiation range up to the $1 \%$ limit within certain limits, UV-induced damage can be reversed by radiation of suitable wavelengths. Under such circumstances the UV tolerance of the corals is significantly increased (Fig. 3, compare A and B).

The experiments in which the effects of photoreactivation were studied as a function of the different spectral bands of visible light indicate that the mortality of the corals decreased depending on the wavelength interval of the light used (Fig. 4). The spectral band around $450 \mathrm{~nm}$ was found to be most effective; a mortality of only $20 \%$ was observed instead of a mortality of $100 \%$ as observed with UV + darkness. This value was established as 1 in Fig. 4. The results from experiments with Favia favus agree in principle with those obtained earlier with Favia pallida (Siebeck \& Böhm 1986). In both cases, however, the question remains as to the extent to which even shorter wavelengths could induce this recovery effect. The results also appear to agree in principle with the action spectra obtained for the planktonic crustaceans Daphnia pulex obtusa and Daphnia galeata using a monochromator system. In these organisms too, maximal effectiveness is found around $460 \mathrm{~nm}$ (Siebeck \& Böhm 1986).

The demonstration of a recovery effect suggested the possibility of repeating the experiments described in the previous section, but exposing the corals to artificial white light both during irradiation and for $48 \mathrm{~h}$ thereafter to differentiate between $\mathrm{LD}_{50} \mathrm{l}$ and $\mathrm{LD}_{50} \mathrm{~d}$. These experiments, carried out in 1987, differ from the earlier ones $(1981,1984)$, where the white light exposure was always carried out after UV irradiation (Siebeck \& Böhm 1986).

The difference in the $\mathrm{LD}_{50}$, dependent on the experimental procedure, is given as a ratio in which the $L D_{50}$ determined without white light irradiation $\left(L_{50} d\right)$ is set as 1 (Table 2). Hence, the dose modification factor (DMF) is the $\mathrm{LD}_{50}$ with white light exposure relative to the value without white light exposure: $\mathrm{DMF}=\mathrm{LD}_{50} \mathrm{l} /$ $\mathrm{LD}_{50} \mathrm{~d}$, where $\mathrm{l}=$ with visible light irradiation after UV exposure; $\mathrm{d}=$ with darkness after UV exposure.

Table 2 shows the DMF values to lie, on average, around 6 . Thus, UV tolerance increases by this factor when the corals are irradiated not only with UV-light, but simultaneously and for another $48 \mathrm{~h}$ thereafter with white light. It is not known whether this recovery effect can be enhanced, for instance, by increasing the light intensity during the recovery period. The UV-fluorescent tubes also emit some, albeit very little, short wavelength visible light. Hence, limited recovery must be considered possible even in experiments without additional exposure to white light. It is possible to eliminate this portion of visible light by using a filter (Schott filter SKF 31 - refer to Fig. 2), but this considerably reduces the UV-intensity. To achieve high doses 
Table 2. Relative $\mathrm{LD}_{50}$ values with white light irradiation $\left(L_{50} L\right)$ and with darkness (LD $\left.D_{50} d\right)$ after UV exposure. Differences between original data $\left(L D_{50} \mathrm{l}-\mathrm{L} \mathrm{D}_{50} \mathrm{~d}\right)$ are significant at $95 \%$ confidence level. All corals were collected in shallow water up to $1.5 \mathrm{~m}$

\begin{tabular}{lcc|}
\hline Species & Ld $_{50} \mathrm{~d}$ & LD $_{50} \mathrm{l}$ \\
\hline Goniastrea edwardsi & 1 & 5.8 \\
Goniastrea pectinata & 1 & 6.3 \\
Favia matthei & 1 & 6.8 \\
Favia favus & 1 & 5.6 \\
Favia pallida & 1 & 5.2 \\
Favites complanata & 1 & 7.3 \\
Platygyra sinensis & 1 & 5.9 \\
\hline
\end{tabular}

$\left(\mathrm{J} \mathrm{m}^{-2}\right)$ similar to those that can be attained briefly without using a filter, one must extend the irradiation interval accordingly. As the corals' tolerance to adequately extended periods in the small irradiation vessels is poor, this is not a feasible approach.

Whenever it is not possible to use a filter to absorb the residual short wavelength visible light from the UV lamp it will also not be possible to totally rule out photoreactivation during UV irradiation. Under these circumstances, therefore, the calculated $\mathrm{LD}_{50} \mathrm{~d}$ values might be somewhat high, and the DMF values somewhat too low. Hence, it cannot be ruled out that the DMF values might, in fact, be greater than those cited in this paper

\section{UV-induced damage and its influence on non-irradiated polyps}

The most conspicuous symptom of advanced UV damage is the extrusion of mesenterial filaments through the mouth opening and entire body surface of the polyp. As long as the filaments emerge from the mouth and only sporadically through the body surface, recovery will still be possible, even without white light. When the irradiated body surface has become thickly covered with mesenterial filaments, however, death is unavoidable, even with exposure to white light. Relatively seriously damaged polyps (exhibiting a moderate density of emergent mesenterial filaments; Fig. 5A) which would otherwise die under conditions of darkness and in standing but well-aerated water, can survive under the same conditions as long as they are kept in running water.

When 2 corals of different species or genera, one irradiated with a sufficiently high but not necessarily lethal UV dose, are placed together in one vessel, after a certain time the polyps of the non-irradiated coral develop the same symptoms as the irradiated specimen although not to the same extent and always without lethal consequences.

Fig. 6 illustrates the change in concentration of dissolved organic carbon (DOC) as a function of time after UV-B-irradiation. For the first few hours after UV exposure, the DOC concentration remains initially low but then increases rapidly (Fig. 6). Extrusion of mesenterial filaments from corals in Vessel $A$ was observed at the same time as the DOC excretion increased (H. R. Müller 1984 pers. comm.). As maximum DOC concentration was reached, the corals in Vessel $B$ began to extrude their mesenterial filaments. The corals in Vessel A were then exposed to white light after UV irradiation, thus providing good conditions for recovery. The DOC concentration decreased and the mesenterial filaments ultimately withdrew from the body surface.

The reaction of the non-irradiated corals must be a consequence of the action of DOC or some of its components. Tests with other organic substances set free when polyps, worms or snails are mechanically killed, for example, elicit no such reactions in the corals. It has also been established that the substances responsible for the reaction described are not derived from the effects of UV-light without the corals. If a non-irradiated coral is placed in Vessel A for the time normally required to prepare the experiment and for UV exposure, and the contents of the vessel are irradiated after removal of the coral, no reaction occurs in the coral in Vessel B.

In numerous experiments (Table 3 ) carried out on the basis of the procedure described, positive effects i. e. communication of the damage response $(+)$ could be detected and predominated when 2 different species or members of different genera were used. The number of exceptions (-) is, however, large and cannot be overlooked. When corals of the same species are placed together, negative effects predominate, i. e. no communication is detected $(-)$. In this case too, there are exceptions $(+)$. It has been proved without exception, however, that irradiation-damaged polyps do not communicate damage to their non-irradiated neighbours within the same colony. This is so even in the extreme situation where a single polyp, in the center of a colony otherwise irradiated with a high UV dose, is screened off with aluminium foil. This polyp shows no damage (Fig. 5A) Along the periphery of the irradiated area, it can be seen that extrusion of mesenterial filaments is confined to the irradiated area.

\section{DISCUSSION}

The investigations show that UV tolerance differs among different coral species, and even within the same species when taken from different sites (in par- 

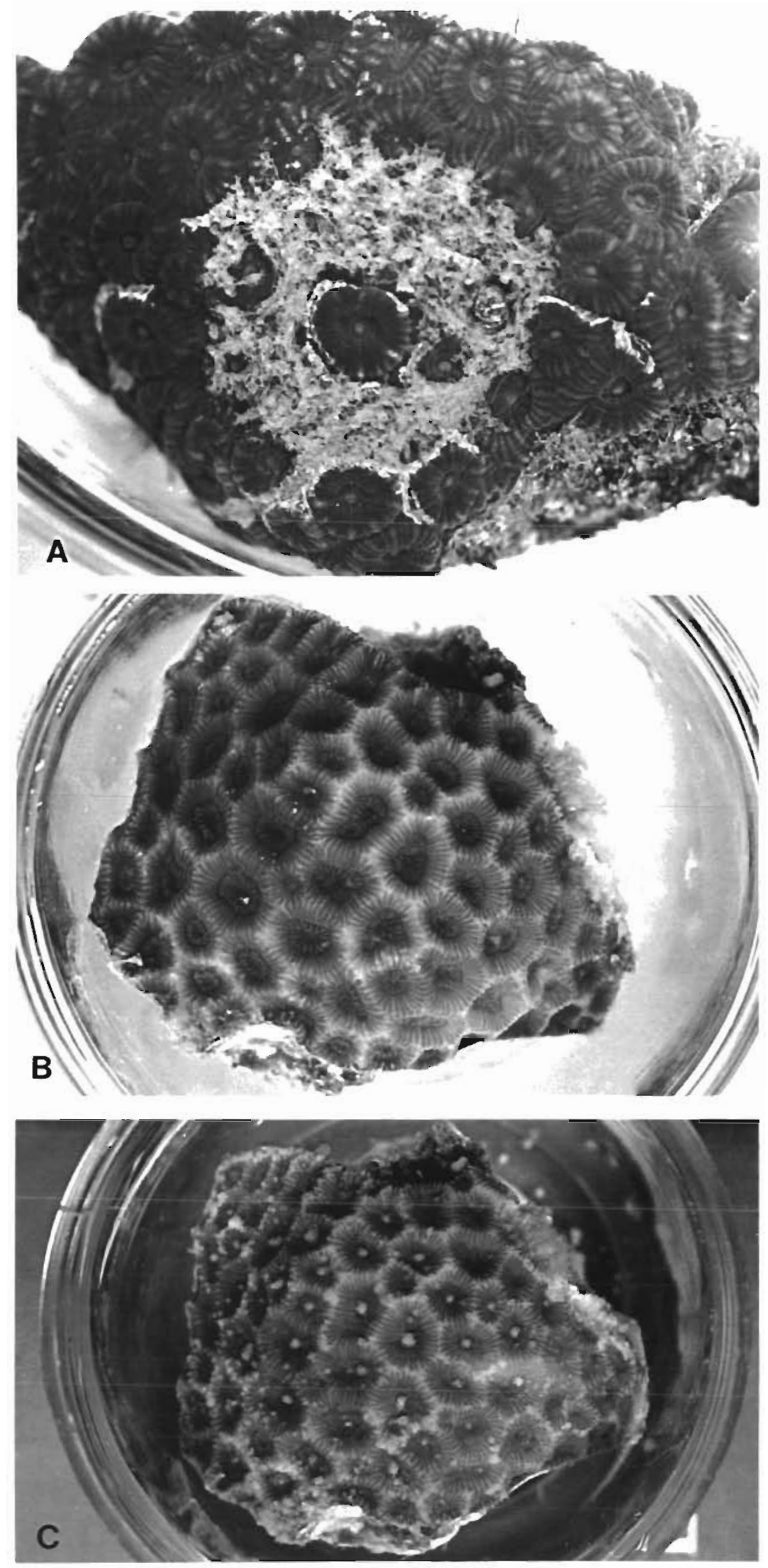

Fig. 5. (A) Montastrea curta. Serious damage to polyps in the irradiated field with the exception of the central polyp which had been screened during the irradiation. (B) Favites complanata before contact with a radiation-damaged coral. (C) Favites complanata. The same piece of coral as before but after $18 \mathrm{~h}$ contact with a radiation-damaged coral (M. curta) 


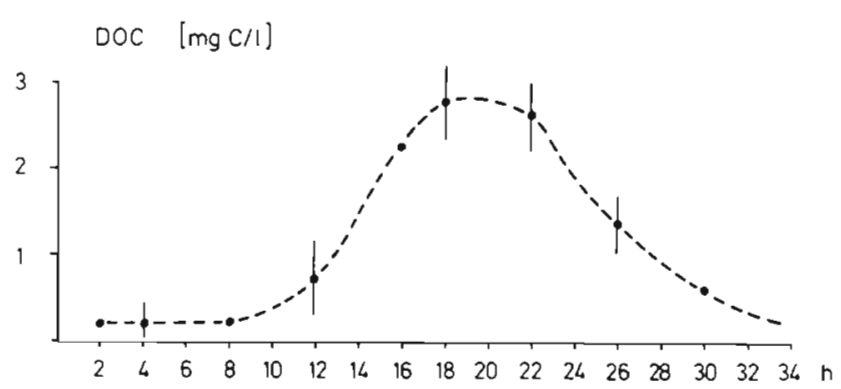

Fig. 6. Changes in DOC concentration during $32 \mathrm{~h}$ after UVexposure (dose $50 \mathrm{~kJ} \mathrm{~m}^{-2}$ ) expressed as $\mathrm{mg} \mathrm{Cl}^{-1}$ Vertical lines indicate $95 \%$ confidence intervals

Table 3. Communication of damage $(+)$ or no communication of damage (-) in individual experiments

\begin{tabular}{|c|c|c|c|c|}
\hline & \multicolumn{4}{|c|}{ Irradiated corals } \\
\hline & $\begin{array}{l}\text { Goniastrea } \\
\text { edwarsi }\end{array}$ & $\begin{array}{l}\text { Favia } \\
\text { matthei }\end{array}$ & $\begin{array}{c}\text { Favites } \\
\text { complanata }\end{array}$ & $\begin{array}{r}\text { Platygyra } \\
\text { sinensis }\end{array}$ \\
\hline $\begin{array}{l}\text { Goniastrea } \\
\text { edwardsi }\end{array}$ & $\begin{array}{l}---- \\
--++\end{array}$ & $\begin{array}{l}++++ \\
+-++\end{array}$ & $\begin{array}{l}++++ \\
-++-\end{array}$ & $\begin{array}{l}++++ \\
--+-\end{array}$ \\
\hline $\begin{array}{l}\text { Favia } \\
\text { matthei }\end{array}$ & $\begin{array}{l}-+++ \\
+-++\end{array}$ & $\begin{array}{l}---- \\
-+--\end{array}$ & $\begin{array}{l}++++ \\
+-+-\end{array}$ & $\begin{array}{l}++++ \\
-+--\end{array}$ \\
\hline $\begin{array}{l}\text { Favites } \\
\text { complanata }\end{array}$ & $\begin{array}{l}++++ \\
-+++\end{array}$ & $\begin{array}{l}++++ \\
++++\end{array}$ & $\begin{array}{l}---- \\
--+-\end{array}$ & $\begin{array}{l}++++ \\
+-++\end{array}$ \\
\hline $\begin{array}{l}\text { Platygyra } \\
\text { sinensis }\end{array}$ & $\begin{array}{l}+++- \\
++--\end{array}$ & $\begin{array}{l}++++ \\
+-++\end{array}$ & $\begin{array}{l}++++ \\
--++\end{array}$ & $\begin{array}{l}---- \\
--+-\end{array}$ \\
\hline
\end{tabular}

ticular from different depths). It may be assumed that the depth-dependent differences in $\mathrm{LD}_{50}$ (Table 1) reflect differences in the concentration of UV-absorbing compounds.

It is thus possible to interpret this finding in light of the results presented by Maragos (1972), who found that in Porites lobata the concentration of the UVabsorbing compounds first described by Shibata (1969) decreases as depth increases. Dunlap et al. (1986), who were able to identify important components of the mixture (S-320) described by Shibata (1969), also showed that, in Acropora spp., the concentration of these substances decreased with increasing depth.

The species shown in Table 1 and Fig. 3 have not yet been investigated with respect to UV-absorbing compounds. Conversely, nothing is known about the UV tolerance of those species in which such compounds have been shown. Nevertheless, based on the results from these different species, it appears likely that there may be a correlation between UV tolerance and the concentration of UV-absorbing compounds.

In accordance with the findings of Dunlap et al. (1986), no further increase in UV sensitivity occurs at depths greater than approximately $20 \mathrm{~m}$. Given this assumption, the following picture emerges: differences in the concentration of UV-absorbing compounds give rise to differences in UV tolerance by a factor of about 2. By exploiting radiation effective for the recovery effect, the UV tolerance can be increased by a factor of at least 6 . However, results available as yet suggest that this increase in UV tolerance is not depth-dependent (Fig. 3, compare A and B). This is shown by the fact that the factor is the same for samples collected in both deep and shallow waters.

To summarize the results of this kind of experiment, it can be said that the depth-dependent differences in the concentration of UV-absorbing compounds in Acropora spp. as described by Dunlap et al. (1986), and the observations described in this paper - albeit for corals of different genera - which show depth-dependent differences in tolerance, can be interpreted on the basis of the existence of a mechanism responsible for screening out UV radiation. The existence of a further mechanism is indicated by the recovery effect made possible by short wavelength visible light. UV tolerance thus consists of a combined effect of at least 2 different physiological mechanisms.

UV tolerance determined under laboratory conditions and under the exclusive use of UV radiation does not allow one to draw conclusions concerning UV tolerance under natural radiation conditions. This also is the case for the UV tolerance determined in this paper, since neither the UV quality of the lamp used nor the visible light quality of the white light lamps correspond to the relevant spectral bands of natural sunlight. A considerable deviation from natural conditions also occurs insofar as the corals in the laboratory experiments were irradiated not only during but also after UV exposure with white light. The data determined in this paper draw attention to the existence of differences in principle in UV tolerance and of different mechanisms of tolerance. They provide a basis for 2 further directions of research: (1) analysis of the physiological mechanisms involved using monochromatic radiation sources, and (2) determination of the prerequisites required to adapt the laboratory findings to situations occurring under natural radiation by means of various combinations of UV and short wavelength visible radiation and of simulated solar radiation.

An important finding is the effect which irradiated samples have on non-irradiated corals. It is conceivable that UV-induced primary damage causes secondary damage which in turn causes damage by releasing substances which either regulate or are involved in the reaction leading to the extrusion of mesenterial filaments. This supposition is supported by the following observations: (1) the existence of a temporal correlation between the maximum DOC concentration and the extrusion of mesenterial filaments in the non-irradiated coral; (2) the existence of a temporal correlation between the decrease in DOC and the withdrawal of 
the mesenterial filaments; (3) the recovery brought about by running water; (4) the transfer (communication) of damage from the irradiated to non-irradiated coral. The fact that the extent of damage (extrusion of mesenterial filaments) after communication does not reach that attained after direct irradiation could be explained by the probability that the concentration of the substances in question is higher at its site of origin than at the site of reception due to dilution caused by transport through water. Moreover the non-irradiated coral does not suffer from primary damage as does the irradiated specimen.

How is damage communicated preferentially to other species? The following attempt at an interpretation is based on the observation that polyps from the same colony never communicate damage to one another, whereas, in the case of polyps of the same species but from another colony, communication is at least possible, although unusual. Since polyps of the same species but from a different colony have, at most, the same degree of genetic identity as polyps from the same colony, it is conceivable that the degree of relationship is the most important criterion determining whether or not communication takes place. In other words, the smaller the genetic identity, the more probable is communication of damage. This postulation allows all the experimental results to be interpreted with the exception of those cases where no communication occurs between different species, but here it is feasible that the relevant substances did not reach the threshold concentration.

An important observation is that communication only accurs at relatively high DOC concentrations $(\sim 2 \mathrm{mgC}$ $1^{-1}$ ). The compounds necessary for communication are apparently at their highest concentration when the DOC concentrations do not occur under natural conditions on account of water exchange and dilution effects. Hence, it follows that the communication observed under experimental conditions is not possible under natural conditions. Interest should thus be concentrated on the apparently well-functioning avoidance of damage communication between polyps from the same colony. The effect of dilution is not relevant in this respect, even under natural conditions, since transport does not occur via the water surrounding the polyps but via the exothecalean space.

A less likely interpretation but one not to be completely excluded would be the idea that a defence reaction is initiated under the influence of the substance(s) released by the radiation-damaged polyps. This would possibly resemble that observed when corals of different species come into close contact with one another (Lang 1973, Connell 1976. Wellington 1980). In these cases, however, mesenterial filaments are never extruded through the body surface. This suggests that the first explanation is more plausible.
To summarize: the interspecific trigger as opposed to an intraspecific trigger in the extrusion of mesenterial filaments should be due to an immunological response between the corals (Hildemann et al. 1977). A final answer to these questions requires knowledge of the identity of the relevant compound(s) and of the extent to which the different samples are genetically identical.

In concluding, consider an entirely different question. What advantage does the protective mechanism described above afford the corals? The answer is easy. Avoidance of damage communication means that radiation damage is confined to that area directly damaged by the radiation. Because coral surfaces in the natural habitat are inclined at various angles with respect to the radiation source, the damaged portion will always represent only a part of the total coral surface. The spread of secondary damage outside this area would represent a serious threat. The evolution of a protective mechanism to avoid this would thus be vital.

Acknowledgements. I particularly thank the present director. Dr J. Baker, and the former director, Dr J. Bunt, of the Australian Institute of Marine Science, Townsville, for providing me with work facilities, accommodations and extensive support. Many colleagues helped in procuring the corals: I thank Drs R. Strickler, T Done, R. Bradbury, D. Klumpp, R. Reichelt, J. Stoddart, P. Sammarco and most particularly Ch. Veron for identifying the corals. I am much indebted to A. Nott for much help during my last stay. The research was supported by the Deutsche Forschungsgemeinschaft $(1981,1984)$ and by the Gesellschaft für Strahlen- und Umweltforschung mbH, Munich (1987).

\section{LITERATURE CITED}

Calkins, J. (ed.) (1982). The role of solar ultraviolet radiation in marine ecosystems. Plenum Press, New York

Connell, J.H. (1976). Competitive interactions and the specific diversity of corals. Mackie, G. O. (ed.) Coelenterate ecology and behaviour. Plenum Press, New York, p. $51-58$

Damkaer, D. M., Dey, D. B., Heran, G. A., Prentice, E. F. (1980). Effects of UV-B radiation on nearsurface zooplankton of Puget Sound. Oecologia (Berl.) 44: 149-158

Dunlap, W. C., Chalker, B. E. (1986). Identification and quantitation of near UV absorbing compounds $(\mathrm{S}-320)$ in a hermatypic scleractinian. Coral Reefs 5: 135-195

Dunlap, W. C. Chalker, B. E., Oliver, J. K, (1986). Bathymetric adaptations of reefbuilding corals at Davies Reef. Great Barrier Reef, Australia. [II. UV-B absorbing compounds. J. exp. mar. Biol. Ecol. 104: in press

Farman, J. C., Gardiner, B. G., Oliver, J. K., (1986). Large losses of total ozone in Antarctica reveal seasonal $\mathrm{ClO}_{\mathrm{x}} f$ $\mathrm{NO}_{x}$ interaction. Nature, Lond. 315: 207-210

Hildemann, W. H., Raison, R. L., Hull, C. J., Akaka. L.. Okumoto, J., Cheung, G. (1977). Tissue transplantation immunity in corals. In: Proceedings Third International Coral Reef Symposium, Rosenstiel School of Marine and Atmospheric Science, Univ of Miami, Miami, p. 537-543

Jerlov, N. G. (1950). Ultraviolet radiation in the sea. Nature, Lond. 116: 111-112 
Jokiel, P. L. (1980). Solar ultraviolet radiation and coral reef epifauna. Science 207: 1069-1071

Karanas, J. J. (1979). Impact of UV-B radiation on the fecundity of the copepod Acartia clausii. Mar. Biol. 65: $125-133$

Kiefer, J., Wienhard, I. (1977). Biologische Wirkungen. In: Kiefer, J. (ed.) Ultraviolette Strahlen. Walter de Gruyter, Berlin, p. 445-56?

Lang, J. C. (1973). Interspecific aggression by scleractinian corals. 2. Why the race is not only to the swift. Bull. mar. Sci. 23: $260-279$

Maragos, J. E. (1972). A study of the ecology of Hawaiian reef corals. Ph.D dissertation, University of Hawaii

Müller, H. R., Banderanayaka, W. M. (1983). An automatic method for the determination of dissolved organic carbon in seawater using continuous thin film oxidation. Mar. Chem. 12: 59-68
Shibata, K. (1969). Pigments and a UV-absorbing substance in corals and a blue-green alga living in the Great Barrier Reef. Pl. Cell Physiol. Kyoto 10: 325-335

Siebeck, O. (1981). Photoreactivation and depth-dependent UV tolerance in reef coral in the Great Barrier Reef/ Australia. Naturwissenschaften 67: 426

Siebeck, O., Böhm, U. (1986). Untersuchungen zur Wirkung der UV-B-Strahlung auf kleine Wassertiere. BPT-Bericht, Gesellschaft für Strahlen- und Umweltforschung, München 1, p. 84

Wellington, G. M. (1980). Reversal of digestive interactions between Pacific reef corals: mediation by sweeper tentacles. Oecologia (Berl.) 47. 340-343

Worrest, R. C. (1982). Review of literature concerning the impact of UV-B radiation upon marine organisms. In: Calkins J. (ed.) The role of solar ultraviolet radiation in marine ecosystems. Plenum Press, New York, p. 429-457

This article was submitted to the editor; it was accepted for printing on December 30, 1987 